OPEN ACCESS

Edited by:

Allan Young,

King's College London,

United Kingdom

Reviewed by:

Rebecca Strawbridge,

King's College London,

United Kingdom

Andrea Fagiolini,

Università degli Studi di Siena, Italy

Muhammad Ishrat Husain,

University of Toronto, Canada

*Correspondence:

Iria Grande

igrande@clinic.cat

Eduard Vieta

evieta@clinic.ub.es

tThese authors have contributed equally to this work

Specialty section:

This article was submitted to

Mood and Anxiety Disorders,

a section of the journal

Frontiers in Psychiatry

Received: 26 June 2018 Accepted: 07 September 2018

Published: 04 October 2018

Citation:

Lopez-Fernandez E, Sole B, Jimenez E, Salagre E, Gimenez A, Murru A,

Bonnín CM, Amann BL, Grande I,

Vieta E and Martínez-Aran A (2018) Cognitive Remediation Interventions in

Schizoaffective Disorder: A Systematic

Review. Front. Psychiatry 9:470.

doi: 10.3389/fpsyt.2018.00470

\section{Cognitive Remediation Interventions in Schizoaffective Disorder: A Systematic Review}

\author{
Ester Lopez-Fernandez ${ }^{1,2 \dagger}$, Brisa Sole ${ }^{2 \dagger}$, Esther Jimenez ${ }^{2}$, Estela Salagre ${ }^{2}$, \\ Anna Gimenez ${ }^{3}$, Andrea Murru², Caterina del Mar Bonnín ${ }^{2}$, Benedikt Lorenz Amann ${ }^{4,5,6}$, \\ Iria Grande ${ }^{2 *}$, Eduard Vieta ${ }^{2 *}$ and Anabel Martínez-Aran ${ }^{2}$ \\ ${ }^{1}$ Unidad de Patología Dual, Hospital Santa Maria, Gestió de Serveis Sanitaris, Lleida, Spain, ${ }^{2}$ Barcelona Bipolar Disorders \\ Program, Institute of Neurosciences, IDIBAPS, CIBERSAM, Hospital Clinic, University of Barcelona, Barcelona, Spain, \\ ${ }^{3}$ Institute of Neurosciences, Hospital Clinic, University of Barcelona, Barcelona, Spain, ${ }^{4}$ Centro Fórum Research Unit, \\ CIBERSAM, Institut de Neuropsiquiatria i Addiccions, Hospital del Mar, Barcelona, Spain, ${ }^{5}$ Department of Psychiatry, Institut \\ Hospital del Mar d'Investigacions Mèdiques, Barcelona, Spain, ${ }^{6}$ Department of Psychiatry, Autonmous University Barcelona, \\ Barcelona, Spain
}

Background: Patients with schizoaffective disorder (SAD) suffer from cognitive impairment, which negatively influences their functionality. Cognitive remediation (CR) interventions have been shown to be effective in patients with schizophrenia (SZ) and bipolar disorder (BD), but evidence in SAD is limited so far. The aim of this study is to systematically review the published data on $\mathrm{CR}$ interventions, either in neurocognition or social cognition, in patients with SAD.

Methods: We conducted a comprehensive, computerized literature search using terms related to CR interventions in psychotic and affective disorders, and particularly in SAD. Pubmed, Embase, and Web of Knowledge databases were used up to February 28th, 2018 according to the Preferred Reporting Items for Systematic Reviews and Meta-Analyses (PRISMA) statement. The search returned 2672 articles of which four were finally selected meeting the inclusion criteria.

Results: Cognitive Enhancement Therapy, computerized Cognitive Remediation Therapy and Cognitive Training showed positive results in subsamples of patients with SAD regarding neurocognition and functioning in comparable terms to patients with schizophrenia as well as in a greater extent in quality of life. Benefits in social cognition were also described when Social Cognition Interaction Training was considered in patients with SAD.

Conclusions: CR interventions seem to improve neurocognition and social cognition in patients with SAD as well as functioning and quality of life. However, further randomized controlled trials on CR interventions with an optimized design focusing on selected sample of patients with SAD are imperative.

Keywords: schizoaffective disorder, affective psychosis, cognitive enhancement, cognitive remediation, cognitive rehabilitation, cognitive training 


\section{INTRODUCTION}

Cognitive impairment is highly prevalent in several mental disorders, especially in those presenting with psychotic symptoms (1-5). Therefore, a neuropsychological examination of patients with psychiatric disorders has been progressively integrated in the elementary assessment of these patients $(6,7)$. Cognitive impairment has been widely studied in patients with schizophrenia (SZ), who usually exhibit some cognitive dysfunction preceding the illness onset (8). The most prevalent impaired cognitive domains in these patients are attention, processing speed, working memory, and problem solving (9-11). Cognitive impairment is also common in bipolar disorder (BD) even during euthymia (12-15). Although a subgroup of patients with $\mathrm{BD}$ may present some mild cognitive deficits before illness onset or even a higher cognitive performance than healthy population, most patients present an average cognitive performance until the first episode (16-18). After illness onset, cognitive performance in $\mathrm{BD}$ declines in particular in the domains of attention, verbal learning and memory, and executive functions according to clinical severity and number of relapses $(8,13,19)$. Therefore, in general terms, there are many similarities between SZ and BD including scope of cognitive domains $(20,21)$.

First descriptions on cognitive performance of patients with schizoaffective disorder (SAD) come from studies with mixed samples of patient with SAD and SZ (22-24). Later, comparisons on the cognitive performance between SAD and SZ were also published (25-33). On the one hand, studies suggested that both groups of patients might present a similar pattern of neurocognitive impairment, especially in memory, executive functions, cognitive flexibility, reasoning, and problem solving (25-28). On the other hand, subsequent studies described less severity of neurocognitive impairment in patients with SAD compared to patients with SZ (29-33). Concerning social cognition, patients with SAD displayed a higher performance on tasks related to the Theory of Mind (ToM) compared to patients with SZ (32). When comparing the neurocognitive performance between patients with $\mathrm{SAD}$ and $\mathrm{BD}$, poorer execution in verbal memory and occupational functioning has been detected in patients with SAD (4). All in all, these findings evidence the cognitive heterogeneity in patients with $\operatorname{SAD}(31,34)$ and place this disorder in an intermediate position in terms of cognitive performance between SZ and BD although possibly closer to SZ (35). In terms of structural neuroimaging abnormalities, SAD also resembles more SZ than BD (36).

Since cognitive impairment is related to a worse clinical course and poor functional outcome $(3,37-40)$, it needs to be considered as a therapeutic clinical target in order to improve both psychosocial functioning and quality of life of patients with SAD (41-44). Nowadays some studies have suggested that social cognition may explain more functional outcome variance than neurocognition and that is why social cognition has been increasingly considered as another important treatment target $(45,46)$. Cognitive remediation (CR) interventions in psychiatric disorders are psychological or pharmacological based approaches (42). Concerning pharmacological treatments in affective and psychotic disorders, evidence so far suggests only a small effect on cognitive improvement; several drugs with potential procognitive effects are currently being investigated (47, 48). With regards to psychological approaches, CR interventions have been developed to improve cognitive processes such as attention, memory, executive function, social cognition, and metacognition (Cognitive Remediation Experts Workshop, April, 2010) (49, 50).

The evidence of CR in neurocognition and social cognition in patients with SAD mainly stems from mixed sample studies, generally of patients with SAD and SZ or in fewer cases patients with SAD and BD (51). Although there are no studies focused exclusively on analyzing the efficacy of cognitive interventions in samples composed by patients with SAD, a systematic review about cognitive rehabilitation on patients with SAD as well as affective disorders hinted an improvement on the level of cognitive performance after completion of cognitive remediation in patients with SAD (52). The data of SAD in this study were determined by estimated pooled effect size (ES) weighted for the percentage of patients with SAD. Potential changes in other outcomes apart from cognition, such as social cognition, psychosocial functioning, and quality of life were not analyzed. According to the lack of knowledge of CR interventions in patients with $\mathrm{SAD}$, we aimed to systematically review the evidence on $\mathrm{CR}$ interventions in neurocognition, social cognition, psychosocial functioning, and quality of life in patient with SAD exclusively and describe their possible benefits in these particular patients.

\section{METHODS}

This systematic review was conducted following the Preferred Reporting Items for Systematic reviews and Meta-Analyses (PRISMA) guidelines (53).

\section{Data Sources and Search Terms}

A comprehensive literature search of CR interventions in SAD was conducted by three authors independently (EL, BS, and IG) using the search terms in Pubmed, Embase, and Web of Science electronic databases from inception to February 28th, 2018.

The following Boolean logic algorithms were used: In Pubmed, (schizoaffective OR schizo-affective OR "affective disorder" OR "affective psychosis" OR "bipolar" OR "manic depression" OR schizophrenia OR "schizophreniform psychosis") AND ("cognition training" OR "cognition therapy" OR "cognitive remediation" OR "cognitive training" OR "cognitive rehabilitation" OR "cognitive therapy" OR "cognitive intervention" OR "cognitive treatment" OR "neurocognitive remediation" OR "neurocognitive training" OR "neurocognitive rehabilitation" OR "neurocognitive therapy" OR "neurocognitive intervention" OR "neurocognitive treatment" OR "neuropsychological training" OR "neuropsychological rehabilitation" OR "neuropsychological therapy" OR "neuropsychological treatment" OR "metacognitive training"); and in Embase and Web of Science: "schizoaffective AND ("cognitive remediation" OR "cognitive rehabilitation" OR "cognitive training"). 
Reference list of individual papers were also examined to identify any additional relevant studies.

\section{Study Inclusion Criteria}

Records were reviewed using the following inclusion criteria: (1) Published studies (randomized clinical trials and follow-up cohort studies) about cognitive interventions targeted at improving cognitive skills, functioning, or quality of life which reported results about the sample or subsample of patients with SAD with at least 2 timing outcomes measures; (2) number or proportion of cases diagnosed with SAD in the sample; (3) diagnoses of SAD according to DSM-III, DSM-III-R, DSM-IV, DSM-IV-TR, DSM-5, ICD-9, or ICD-10; (4) no language restrictions were applied in this review; (5) no comparator group was imperative.

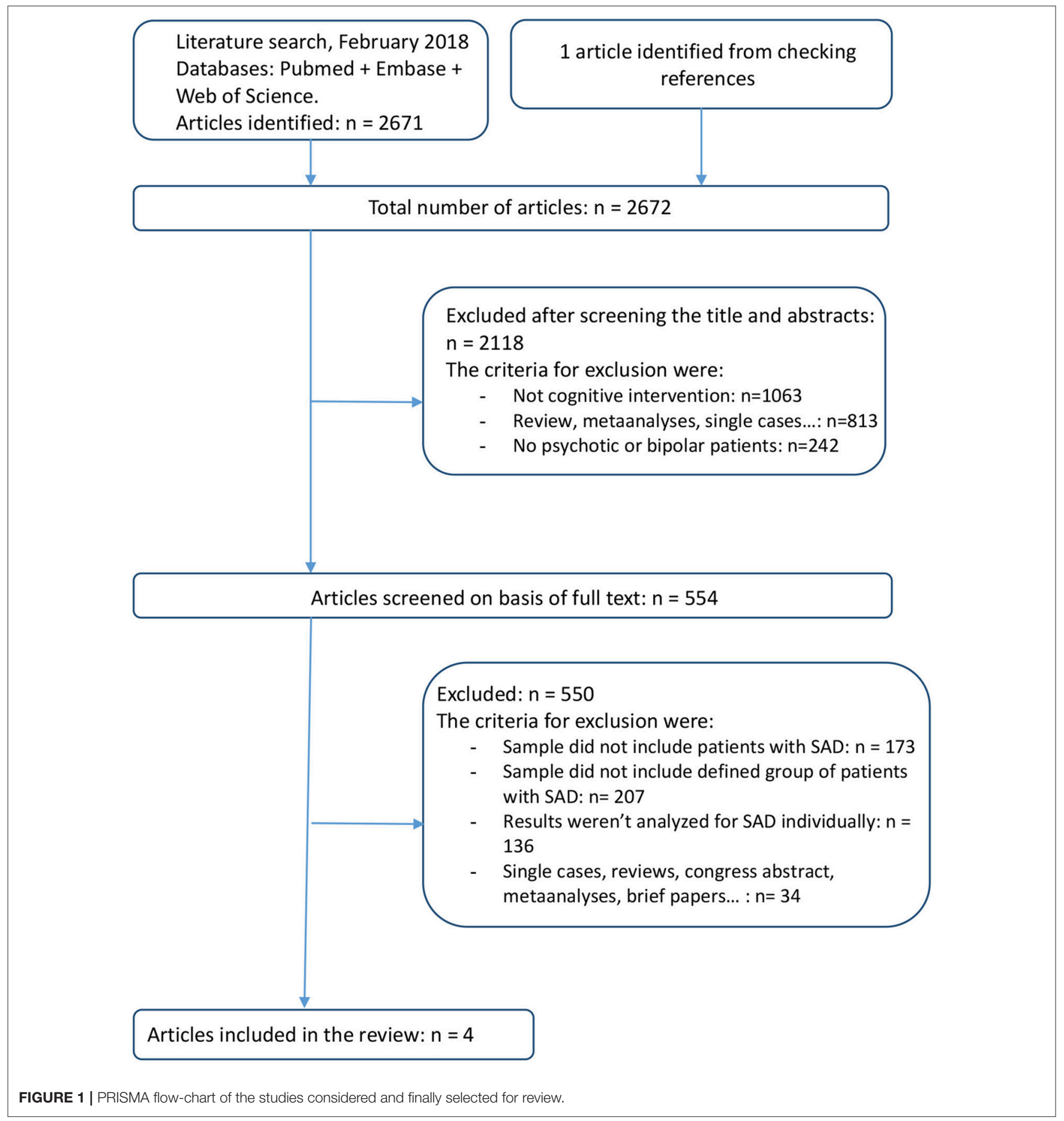




\section{Study Exclusion Criteria}

The exclusion criteria applied were: (1) meta-analyses, systematic or narrative reviews, single cases, cases series, study protocols, letters to the editor, editorials, debate articles, opinion papers or congress abstracts; (2) interventions not involving CR interventions; (3) trials without identifying the number of participants with SAD; (4) studies without concrete outcomes about patients with SAD.

\section{Procedures and Data Extraction}

Articles were selected based on title and abstract and, when necessary, on examination of the full text to assess its relevance. After elimination of duplicated sources, the full texts of the potentially eligible studies were considered. References were also reviewed to identify further possible studies of interest. Most existing articles on this subject about patients with psychosis and $\mathrm{BD}$ were reviewed, since in many cases the sample was mixed and the diagnosis of SAD was not detected in the search.

Extracted information was synthesized in two tables. In Table 1 the characteristics of the selected studies and main results are summarized: (a) first author and year of publication; (b) characteristics of the sample: (c) sample diagnosis; (d) study design; (e) outcome measures; (f) results summary; and (g) limitations. In Table 2 the characteristics of the interventions applied according to the following structure: (a) intervention; (b) target; (c) duration; (d) setting: individual or group intervention; and (e) type: computer assisted or non-computer assisted sessions.

\section{RESULTS}

Using the aforementioned keywords, the search returned 2672 records (Figure 1). The literature search identified 554 potentially relevant studies. After excluding studies that did not include or describe the sample of patients with SAD and their outcomes, four papers were identified according to the inclusion criteria (54-57).

The sample consisted of 73 patients with SAD out of 216 (Table 1).Two studies were performed in USA $(55,57)$, one in Germany (56), and one in Spain (54). The average study global sample size was 54 (SD 22.4) participants ranging from 32 to 89 patients. $58.3 \%$ of participants were men with a mean age of $38.1(S D=9.2)$ years. Three studies reported participants illness duration $(54,55,57)$ which ranged from 3.2 to 30 years with a mean duration of 16.6 (SD 13.9) years. The average percentage of patients with SAD in the four studies was $33.8 \%$ in a range from 10.8 to $44 \%$. The study with the largest sample of SAD was carried by Twamley et al. (57) with a sample of 39 patients. The interventions carried out in each study are described in Table 2.

Lewandowski et al. (55) compared a group that received Cognitive Enhancement Therapy (CET) with another group that received Enriched Supportive Therapy (EST) as a control group in a randomized controlled trial. The total sample included 20 patients with SAD and 38 with SZ. The authors conducted a secondary analysis comparing cognitive outcomes in patients with SAD and SZ with positive findings for CET in both diagnoses. The authors did not find a significant influence of the diagnosis on the relationship between improvement and treatment condition for the domains of processing speed, neurocognition, cognitive style, social cognition, social adjustment, or symptoms. Moreover, they described significant benefits for CET vs. EST for both SAD and SZ in withingroup analysis: social cognition ( $\mathrm{SAD} d=1.69, \mathrm{SZ} \mathrm{d}=1.68$ ); social adjustment ( $\mathrm{SAD} \mathrm{d}=1.36, \mathrm{SZ} \mathrm{d}=1.65$ ); and symptoms (SAD $\mathrm{d}=1.00, \mathrm{SZ} \mathrm{d}=0.68$ ); all $p<0.045$. In patients with SZ, CET produced significant improvement over EST in neurocognition $(\mathrm{d}=0.46, p=0.025)$ and cognitive style $(\mathrm{d}=1.08, p=0.009)$, however only trend-level effects were observed among patients with SAD $(\mathrm{d}=0.52, p=0.089$ and $\mathrm{d}=0.99, p=0.098$, respectively). No significant effect of the diagnosis on clinical improvement was found, with the exception of a significant reduction on depressive and anxious symptoms in patients with SAD $(p=0.019)$. This may be due to higher levels of anxiety and depression at baseline in this group of patients.

The computerized Cognitive Remediation Therapy (cCRT) is the intervention used in the study by Scheu et al. This study sample included 10 patients with SAD and 22 with SZ. After 4 weeks, the authors observed a significant improvement in the neurocognitive performance that involved attention memory, strategy, numeracy and visuo-motor skills in patients with SAD and SZ (56). No significant differences were found in improvement rates between both diagnostic groups. There was no significant correlation between improvement rates and the number of attended training sessions, but better improvement rates were linked to a higher total number of completed tasks $(r=0.36, p<0.05)$. Correlation analyses revealed no significant relationship between any of the baseline cognitive or symptom measures and improvement rates. Cognitive improvements on processing speed and verbal memory were associated with higher baseline scores on the general PANSS and total PANSS ( $r=-0.44, p<0.05 ; r=-0.45, p<0.01$, respectively), while improvements on Trail Making Test A were related to higher scores in the positive PANSS $(r=-0.43, p<0.05)$. Higher scores in the PANSS scores indicated worse clinical state.

Twamley et al. (57) studied the efficacy of Cognitive Training (CT) and Standard Pharmacotherapy (SP) compared to SP alone in a mixed sample of 39 patients with SAD, 45 with SZ and 5 with psychosis not otherwise specified. Patients showed a significant improvement in attention $(p=0.049)$, verbal memory $(p=0.017)$, and negative symptoms severity $(p=0.002)$ at 3-month follow-up and in verbal memory $(p=0.039)$, prospective memory $(p=0.050)$, functional capacity $(p=0.004)$, negative symptoms severity $(p=0.025)$, and self-reported quality of life $(p=0.004)$ at 6 -month follow-up. Results of cognitive outcomes were not available according to diagnoses. However, patients with SAD showed a significant improvement in subjective perception of quality of life at 6 months compared to patients with SZ $(p=0.03)$ (57). At 3-month follow-up, improvement in digit span forward and in Hopkins Verbal Learning Test (HVLT) were associated with higher levels of negative symptoms severity at baseline $(r=0.45, p=0.045$; $r=0.50, p=0.025$, respectively). Moreover, improvement in 


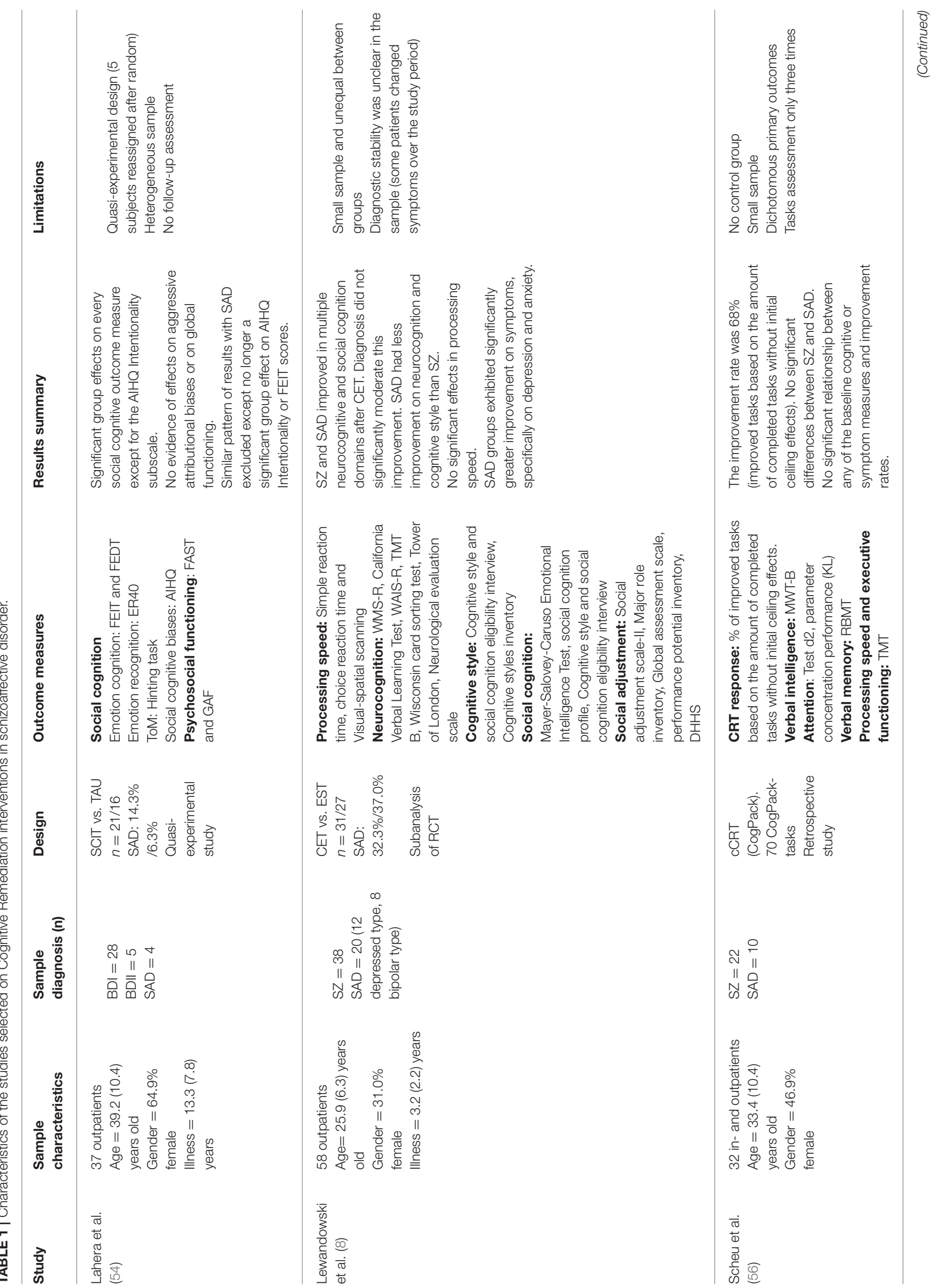




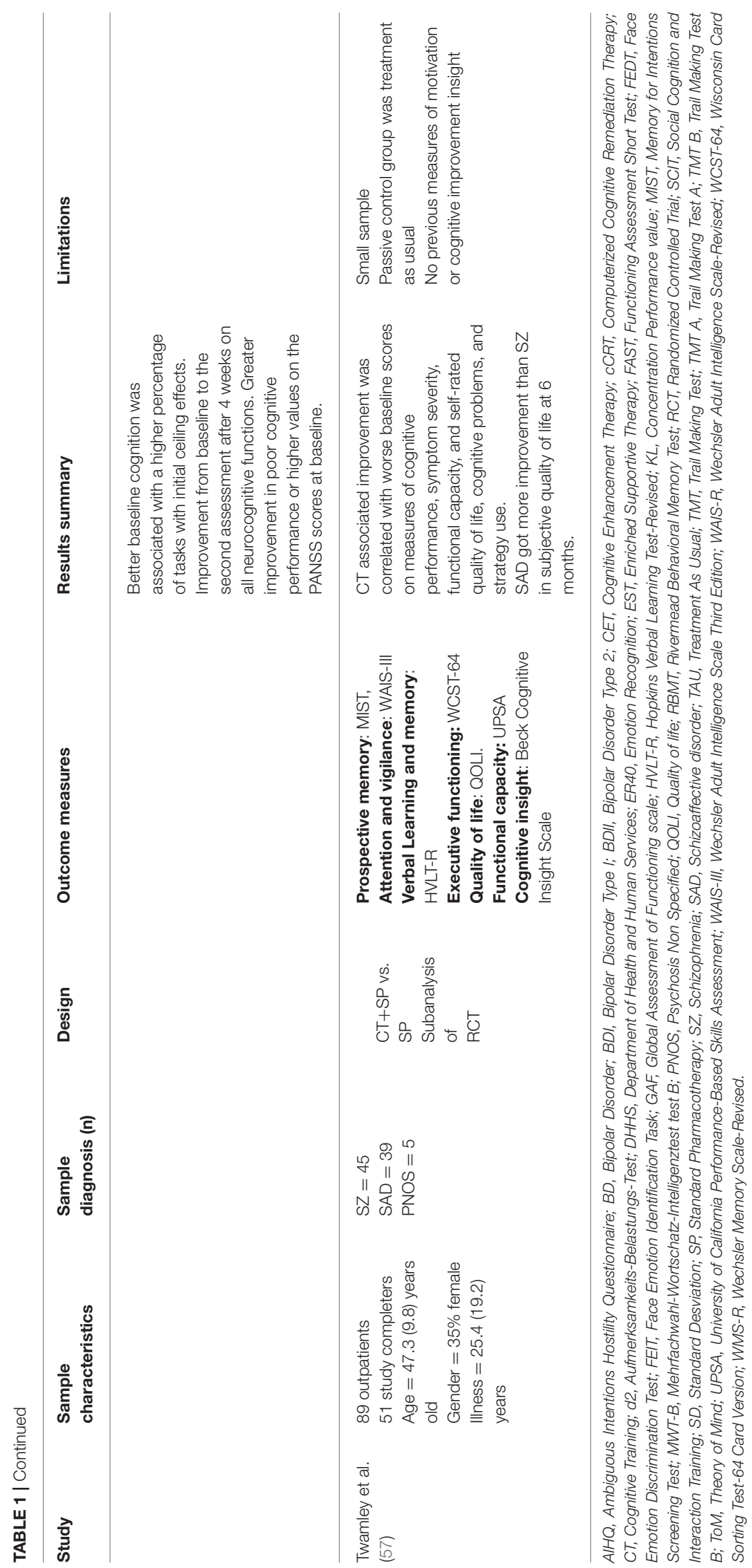


TABLE 2 | Description of the studied Cognitive Remediation interventions in schizoaffective disorder.

\begin{tabular}{|c|c|c|c|c|}
\hline Intervention & Target & Duration & Setting & Type \\
\hline $\begin{array}{l}\text { Cognitive } \\
\text { Enhancement Therapy } \\
\text { (CET) }\end{array}$ & $\begin{array}{l}\text { Cognitive functions and } \\
\text { social cognition }\end{array}$ & $\begin{array}{l}\text { Biweekly sessions ( } 60 \mathrm{~h} \text { cognitive } \\
\text { training }+45 \mathrm{~h} \text { social cognition) } \\
\text { for } 24 \text { months }\end{array}$ & Individual/group & $\begin{array}{l}\text { Computer assisted and } \\
\text { non-computer assisted } \\
\text { sessions }\end{array}$ \\
\hline $\begin{array}{l}\text { computerized Cognitive } \\
\text { Remediation Therapy } \\
\text { cCRT (CogPack) }\end{array}$ & Cognitive function & $\begin{array}{l}50 \text { min sessions twice a week } \\
\text { over a maximum period of } 8 \\
\text { weeks }\end{array}$ & Individual & Computer assisted \\
\hline Cognitive Training (CT) & Cognitive function & $2 \mathrm{~h}$ once a week for 12 weeks & Group & Non-computer assisted \\
\hline $\begin{array}{l}\text { Social Cognition and } \\
\text { Interaction Training } \\
\text { (SCIT) }\end{array}$ & Social cognition & $1 \mathrm{~h}$ once a week for 18 weeks & Group & Non-computer assisted \\
\hline
\end{tabular}

digit span was related to higher levels of self-reported cognitive problems $(r=0.48, p=0.033)$. An improvement in HVLT percent retention at 3 months was also associated with lower cognitive strategy use at baseline $(r=-0.48, p=0.033)$. At 6-month follow-up, improvement on the University of California, San Diego, Performance-Based Skills Assessment (UPSA) functional capacity was associated with higher levels of positive symptoms $(r=0.45, p=0.035)$, lower levels of cognitive strategy use $(r=-0.54, p=0.009)$, and worse UPSA performance at baseline $(r=-0.56, p=0.007)$.

Lahera et al. (54) described the benefits of Social Cognition and Interaction Training (SCIT) compared to Treatment As Usual (TAU) in a mixed sample of 4 patients with SAD and 33 with BD. The authors detected a significant improvement in the group that received SCIT on each social cognitive outcome except for the Ambiguous Intentions Hostility Questionnaire (AIHQ) Intentionality subscale, with a trend to significance ( $p=0.069$ ). The group that received SCIT showed a significant improvement in emotion perception and ToM $(p<0.05)$, and significant improvement in hostile attribution biases compared to the TAU group $(p<0.05)$. The SCIT group showed a withingroup improvement on the AIHQ Blame subscale $(\mathrm{d}=-0.19, p$ $<0.01)$, an improvement in AIHQ Hostility Bias $(\mathrm{d}=-0.55, p<$ $0.05)$, an improvement in scores on the Hinting Task $(\mathrm{d}=0.4, p$ $<0.05$ ), an improvement on the Emotion Recognition-40 (ER40) ( $\mathrm{d}=0.51, p<0.05$ ), and an improvement on the Face Emotion Discrimination Task (FEDT) $(\mathrm{d}=0.67, p<0.01)$ and Face Emotion Identification Task (FEIT) $(\mathrm{d}=0.81, p<0.05)$. Posthoc analysis did not evidence an effect of diagnoses on the results. No evidence for between-group effects on any clinical outcome was found.

The risk of bias was assessed in all eligible studies as recommended by the Cochrane Collaboration (58). However it was difficult to determine due to the heterogeneity of the study design and because the focus of this systematic review was beyond the main objectives of the selected articles.

\section{DISCUSSION}

Despite the scarce number of studies on the topic, there is evidence, although limited, of the effectiveness of CR interventions in patients with SAD. CET, cCRT, and CT showed positive results in cognition in the subsample of patients with SAD considering neurocognitive or functional parameters as well as outcomes related to quality of life. Benefits in social cognition were also described when SCIT as well as CET were considered in patients with SAD.

These results are in line with previous bibliography on the issue. Regarding neurocognition, Anaya et al. (52) described in their meta-analysis that CR interventions showed positive effects on cognition at post-intervention in patients with SAD as well as in patients with affective disorders with an ES of 0.32 . Interestingly, the authors pointed out that the effect of CR interventions increased when the meta-analysis was limited to studies that included exclusively patients with SAD, obtaining a pooled ES weighted for the percentage of patients with SAD of 0.41 . In addition, we also have found some evidence that schizoaffective patients could improve in specific measures of social cognition, social adjustment, symptoms and quality of life after receiving a CR intervention.

It is worth commenting on the studies that presented a relevant percentage of patients with $\mathrm{SAD}$ in the sample but did not specifically mention results of the subsample of patients with SAD. Considering neurocognition, In a subsequent article (59) of the one included in this systematic revision, Twamley et al. described general improvement in cognitive domains considering the entire sample. In another study with $53 \%$ of the sample diagnosed with SAD (60), computerassisted cognitive rehabilitation showed greater improvement in neurocognitive performance, specifically in verbal memory and attention, and negative symptoms compared to a wait-list control group. Regarding social cognition, a recent systematic review that included studies with samples of patients with SAD and SZ (61) stated that interventions in social cognition could improve several domains related to affect recognition, ToM and social perception. However, the effect on attributional style and the relationship between improvement in social cognition and functioning were unclear. All in all, CR interventions in neurocognition and social cognition seem to be effective in the psychotic spectrum.

Whether patients diagnosed with SAD benefit from CR interventions more than SZ or less than $\mathrm{BD}$ is still open to question. Lewandowski et al. published the results of CET between patients with SAD and SZ in a subanalysis of a previous 
study $(55,62)$. Although positive results were described in both groups, a lower benefit of the treatment was observed in the cognitive performance of patients with SAD compared to those with SZ. This may be due to a ceiling effect since patients diagnosed with SZ present more cognitive impairment compared to patients diagnosed with SAD. The evidence suggests that the wider the cognitive impairment at baseline, the greater benefits can be obtained with CR interventions. It may be due to the fact that there is more room for improvement or because of an increased motivation (57). Nevertheless, in the study performed by Scheu et al. (56), outcomes of patients with SAD did not differ from those observed in patient with SZ, being positive in both disorders. Thus, despite the cognitive heterogeneity (31, $34)$, SAD may be placed in an intermediate position in terms of neurocognitive performance between SZ and BD although possibly closer to SZ (35).

There is controversy about how basal clinical state may impact on the results of CR and how CR may influence the clinical state. With regard to the former, on one hand, Wykes et al. (63) reported in a meta-analysis focused on CR in patients with SZ that the benefits were more significant in less symptomatic patients. On the other hand, Twamley et al. (57) found an association between higher levels of negative symptoms and greater benefits, and between higher levels of positive symptoms and greater improvement in functional capacity. Therefore, they consider that the presence or severity of symptoms should not be an exclusion criterion for these interventions. Other authors consider that the severity of positive or negative symptoms does not predict the rate of improvement $(19,56,64)$. Considering the latter, the two meta-analyses by Wykes et al. and McGurk et al. $(63,65)$ described a significant positive effect of CR on both symptoms and functionality in patients with SZ. Lewandowski et al. (55) detected greater improvement in symptoms after receiving CET in patients diagnosed with SAD compared to patients diagnosed with SZ, specifically in anxious and depressive symptoms.

Another issue of debate is the right moment to provide $\mathrm{CR}$ interventions. Some authors suggest that the younger the patients, the more they benefit from CR interventions $(63,66-$ $68,70)$. On the contrary, the two major meta-analysis in the literature about $\mathrm{CR}$ interventions concluded no relationship between these two variables or that the older the patients, the better outcomes of CR interventions $(63,65)$. Twamley et al. pointed out that older patients achieved more improvement, specifically in prospective memory (57). The concept of cognitive reserve may provide an explanation for the discrepancy in these results since it reflects the capacity of the brain to endure neuropathology and successfully complete cognitive tasks (69). Moreover, cognitive reserve has been found as a significant predictor of cognitive and psychosocial functioning in patients with SZ and BD (70-72). Another key issue in CR interventions relates to the relationship between number of sessions and the obtained benefits. The meta-analysis carried out by Wykes et al. (63) and the study of Scheu et al. (56) did not reveal any association between the aforementioned variables. Last but not least, the drop-out ratio is another matter of concern in CR interventions. Twamley et al. (57) analyzed who was more likely to drop out in their randomized controlled trial of CT in which $57.30 \%$ of the patients completed the therapy while $31.46 \%$ did not start it and $11.24 \%$ withdrew. Those who completed CT had more formal education and lower antipsychotic doses than had dropouts with no CT exposure, but the groups did no otherwise differ. In Lewandowski et al. (55) and Lahera et al. (54) studies, the frequencies of dropouts were 20.6 and $19.1 \%$, respectively.

As a summary, Lewandowski et al. (55) obtained small effects on neurocognition in the group of SAD, vs. medium effects in the group of SZ. However, patients with SAD improved more in symptomatology after cognitive treatment. In this study, a similar improvement in the functionality of both groups was obtained. On the other hand, Scheu et al. (56) did not find differences in improvement rates when comparing patients with SAD and SZ. Lahera et al. (54) did not find differences after treatment when compared patients with $\mathrm{SAD}$ and $\mathrm{BD}$, considering that the sample included four patients with SAD. Twamley et al. (57) did not report group differences but more improvement in subjective quality of life at 6 months in SAD compared to patient with SZ.

Despite data gathered in this systematic review seems to support a positive effects of $\mathrm{CR}$ interventions in $\mathrm{SAD}$, these results should be interpreted with caution. First of all, the samples of the four reviewed studies are restricted to small subsamples of patients diagnosed with SAD within a wider sample of patients diagnosed mostly with SZ or BD. Although we only consider articles that studied the concrete subsample of $\mathrm{SAD}$, the obtained results stem from post-hoc analyses, which are not always aligned with the aim of the primary objective of the study and therefore may increase false positive results. Moreover, the heterogeneity of the design of the reviewed CR interventions should be beared in mind. This heterogeneity could partly explain discrepancies among results from these studies.

In this systematic review, scarce studies on CR interventions in SAD were found. However, available data support that CR interventions may improve neurocognition and social cognition in this group of patients. Subsequently, functioning and quality of life on this population may also benefit from improving the daily life of patients with SAD. So as to confirm this hypothesis, further randomized controlled trials on CR interventions with an optimized design and selected sample of patients with SAD are urged.

\section{AUTHOR CONTRIBUTIONS}

All authors listed have made a substantial, direct and intellectual contribution to the work, and approved it for publication.

\section{ACKNOWLEDGMENTS}

CMB would like to thank the Departament de Salut de la Generalitat de Catalunya for the PERIS grant (SLT002/16/00331).

IG is supported by the Instituto de Salud Carlos III, Ministry of Economy and Competitiveness of Spain [Juan Rodés Contract (JR15/00012) and a grant (PI16/00187)] integrated into the Plan Nacional de I $+\mathrm{D}+\mathrm{I}$ and cofunded by ISCIII-Subdirección 
General de Evaluación and Fondo Europeo de Desarrollo Regional (FEDER).

EV thanks the support of the Spanish Ministry of Economy and Competitiveness (PI15/00283) integrated into the Plan Nacional de I $+\mathrm{D}+\mathrm{I}$ y cofinanciado por el ISCIII-Subdirección General de Evaluación y el Fondo Europeo de Desarrollo Regional (FEDER); CIBERSAM; and the Comissionat per a Universitats i Recerca del DIUE de la Generalitat de Catalunya to the Bipolar Disorders Group (2017 SGR 1365) and the

\section{REFERENCES}

1. Albus M, Hubmann W, Wahlheim C, Sobizack N, Franz U, Mohr F. Contrasts in neuropsychological test profile between patients with firstepisode schizophrenia and first-episode affective disorders. Acta Psychiatr Scand. (1996) 94:87-93.

2. Zubieta JK, Huguelet P, O’Neil RL, Giordani BJ. Cognitive function in euthymic bipolar I disorder. Psychiatry Res. (2001) 102:9-20. doi: 10.1016/S0165-1781(01)00242-6

3. Martínez-Arán A, Vieta E, Colom F, Torrent C, Sánchez-Moreno J, Reinares $\mathrm{M}$, et al. Cognitive impairment in euthymic bipolar patients: implications for clinical and functional outcome. Bipolar Disord. (2004) 6:224-32. doi: 10.1111/j.1399-5618.2004.00111.x

4. Torrent C, Martínez-Arán A, Amann B, Daban C, Tabarés-Seisdedos $\mathrm{R}$, González-Pinto A, et al. Cognitive impairment in schizoaffective disorder: a comparison with non-psychotic bipolar and healthy subjects. Acta Psychiatr Scand. (2007) 116:453-60. doi: 10.1111/j.1600-0447.2007. 01072.x

5. Simonsen C, Sundet K, Vaskinn A, Birkenaes AB, Engh JA, Faerden A, et al. Neurocognitive dysfunction in bipolar and schizophrenia spectrum disorders depends on history of psychosis rather than diagnostic group. Schizophr Bull. (2011) 37:73-83. doi: 10.1093/schbul/sbp034

6. Miskowiak K, Burdick K, Martinez-Aran A, Bonnin CM, Bowie CR, Carvalho AF, et al. Methodological recommendations for cognition trials in bipolar disorder by the International Society for Bipolar Disorders Targeting Cognition Task Force. Bipolar Disord. (2017) 19:614-26. doi: $10.1111 /$ bdi. 12534

7. Miskowiak K, Burdick K, Martinez-Aran A, Bonnin CM, Bowie CR, Carvalho AF, et al. Assessing and addressing cognitive impairment in bipolar disorder: the International Society for Bipolar Disorders Targeting Cognition Task Force recommendations for clinicians. Bipolar Disord. (2018) 20:184-94. doi: 10.1111/bdi.12595

8. Lewandowski KE, Cohen BM, Öngur D. Evolution of neuropsychological dysfunction during the course of schizophrenia and bipolar disorder. Psychol Med. (2011) 41:225-41. doi: 10.1017/S0033291710001042

9. Dickinson D, Ramsey ME, Gold JM. Overlooking the Obvious: a meta-analytic comparison of digit symbol coding tasks and other cognitive measures in schizophrenia. Arch Gen Psychiatry (2007) 64:532. doi: 10.1001/archpsyc.64.5.532

10. Heinrichs RW, Zakzanis KK. Neurocognitive deficit in schizophrenia: a quantitative review of the evidence. Neuropsychology (1998) 12:426-45.

11. Palmer BW, Dawes SE, Heaton RK. What Do we know about neuropsychological aspects of schizophrenia? Neuropsychol Rev. (2009) 19:365-84. doi: 10.1007/s11065-009-9109-y

12. Robinson LJ, Thompson JM, Gallagher P, Goswami U, Young AH, Ferrier IN, et al. A meta-analysis of cognitive deficits in euthymic patients with bipolar disorder. J Affect Disord. (2006) 93:105-15. doi: 10.1016/j.jad.2006. 02.016

13. Bourne C, Aydemir O, Balanzá-Martínez V, Bora E, Brissos S, Cavanagh JT, et al. Neuropsychological testing of cognitive impairment in euthymic bipolar disorder: an individual patient data metaanalysis. Acta Psychiatr Scand. (2013) 128:149-62. doi: 10.1111/acps. 12133 project SLT006/17/00357, from PERIS 2016-2020 (Departament de Salut). CERCA Programme/Generalitat de Catalunya.

AM-A thanks the support of the Spanish Ministry of Economy and Competitiveness (PI15/00330) integrated into the Plan Nacional de I+D+I y cofinanciado por el ISCIIISubdirección General de Evaluación y el Fondo Europeo de Desarrollo Regional (FEDER); CIBERSAM) and the project SLT006/17/00177, from PERIS 2016-2020 (Departament de Salut). CERCA Programme/Generalitat de Catalunya.

14. Bortolato B, Miskowiak K, Köhler CA, Vieta E, Carvalho AF. Cognitive dysfunction in bipolar disorder and schizophrenia: a systematic review of meta-analyses. Neuropsychiatr Dis Treat. (2015) 11:3111-25. doi: 10.2147/NDT.S76700

15. Mann-Wrobel MC, Carreno JT, Dickinson D. Meta-analysis of neuropsychological functioning in euthymic bipolar disorder: an update and investigation of moderator variables. Bipolar Disord. (2011) 13:334-42. doi: 10.1111/j.1399-5618.2011.00935.x

16. Martino DJ, Samamé C, Ibañez A, Strejilevich SA. Neurocognitive functioning in the premorbid stage and in the first episode of bipolar disorder: a systematic review. Psychiatry Res. (2015) 226:23-30. doi: 10.1016/j.psychres.2014. 12.044

17. Mollon J, David AS, Zammit S, Lewis G, Reichenberg A. Course of cognitive development from infancy to early adulthood in the psychosis spectrum. JAMA Psychiatry (2018) 75:270-9. doi: 10.1001/jamapsychiatry.2017.4327

18. Vieta E, Berk M, Schulze TG, Carvalho AF, Suppes T, Calabrese JR, et al. Bipolar disorders. Nat Rev Dis Prim. (2018) 4:18008. doi: 10.1038/nrdp. 2018.8

19. Kurtz MM, Gerraty RT. A meta-analytic investigation of neurocognitive deficits in bipolar illness: profile and effects of clinical state. Neuropsychology (2009) 23:551-62. doi: 10.1037/a0016277

20. Bora E, Yücel M, Pantelis C. Cognitive impairment in affective psychoses: a meta-analysis. Schizophr Bull. (2010) 36:112-25. doi: 10.1093/shbul/sbp093

21. Martínez-Arán A, Penadés R, Vieta E, Colom F, Reinares $M$, Benabarre A, et al. Executive function in patients with remitted bipolar disorder and schizophrenia and its relationship with functional outcome. Psychother Psychosom. (2002) 71:39-46. doi: 10.1159/0000 49342

22. Breier A, Schreiber JL, Dyer J, Pickar D. National Institute of Mental Health longitudinal study of chronic schizophrenia. Prognosis and predictors of outcome. Arch Gen Psychiatry (1991) 48:239-46.

23. Brekke JS, Raine A, Ansel M, Lencz T, Bird L. Neuropsychological and psychophysiological correlates of psychosocial functioning in schizophrenia. Schizophr Bull. (1997) 23:19-28.

24. Lysaker PH, Bryson GJ, Davis LW, Bell MD. Relationship of impaired processing speed and flexibility of abstract thought to improvements in work performance over time in schizophrenia. Schizophr Res. (2005) 75:211-8. doi: 10.1016/j.schres.2004.09.014

25. Manschreck TC, Maher BA, Beaudette SM, Redmond DA. Context memory in schizoaffective and schizophrenic disorders. Schizophr Res. (1997) 26:153-61.

26. Evans JD, Heaton RK, Paulsen JS, McAdams LA, Heaton SC, Jeste DV. Schizoaffective disorder: a form of schizophrenia or affective disorder? J Clin Psychiatry (1999) 60:874-82.

27. Gooding DC, Tallent KA. Spatial working memory performance in patients with schizoaffective psychosis versus schizophrenia: a tale of two disorders? Schizophr Res. (2002) 53:209-18. doi: 10.1016/S0920-9964(01)00258-4

28. Reichenberg A, Weiser M, Rabinowitz J, Caspi A, Schmeidler J, Mark M, et al. A population-based cohort study of premorbid intellectual, language, and behavioral functioning in patients with schizophrenia, schizoaffective disorder, and nonpsychotic bipolar disorder. Am J Psychiatry (2002) 159:2027-35. doi: 10.1176/appi.ajp.159. 12.2027

29. Gruber O, Gruber E, Falkai P. Articulatory rehearsal in verbal working memory: a possible neurocognitive endophenotype that differentiates between 
schizophrenia and schizoaffective disorder. Neurosci Lett. (2006) 405:24-8. doi: 10.1016/j.neulet.2006.06.062

30. Heinrichs RW, Ammari N, McDermid Vaz S, Miles AA. Are schizophrenia and schizoaffective disorder neuropsychologically distinguishable? Schizophr Res. (2008) 99:149-54. doi: 10.1016/j.schres.2007. 10.007

31. Goldstein G, Shemansky WJ, Allen DN. Cognitive function in schizoaffective disorder and clinical subtypes of schizophrenia. Arch Clin Neuropsychol. (2005) 20:153-9. doi: 10.1016/j.acn.2004.03.008

32. Stip E, Sepehry AA, Prouteau A, Briand C, Nicole L, Lalonde P, et al. Cognitive discernible factors between schizophrenia and schizoaffective disorder. Brain Cogn. (2005) 59:292-5. doi: 10.1016/j.bandc.2005.07.003

33. Fiszdon JM, Richardson R, Greig T, Bell MD. A comparison of basic and social cognition between schizophrenia and schizoaffective disorder. Schizophr Res. (2007) 91:117-21. doi: 10.1016/j.schres.2006.12.012

34. Bora E, Yucel M, Pantelis C. Cognitive functioning in schizophrenia, schizoaffective disorder and affective psychoses: meta-analytic study. $\mathrm{Br}$ J Psychiatry J Ment Sci. (2009) 195:475-82. doi: 10.1192/bjp.bp.108. 055731

35. Madre M, Canales-Rodríguez EJ, Ortiz-Gil J, Murru A, Torrent C, Bramon E, et al. Neuropsychological and neuroimaging underpinnings of schizoaffective disorder: a systematic review. Acta Psychiatr Scand. (2016) 134:16-30. doi: $10.1111 /$ acps. 12564

36. Amann BL, Canales-Rodríguez EJ, Madre M, Radua J, Monte G, AlonsoLana S, et al. Brain structural changes in schizoaffective disorder compared to schizophrenia and bipolar disorder. Acta Psychiatr Scand. (2016) 133:23-33. doi: 10.1111/acps. 12440

37. Medalia A, Richardson R. What predicts a good response to cognitive remediation interventions? Schizophr Bull. (2005) 31:942-53. doi: $10.1093 /$ schbul/sbi045

38. Green MF, Kern RS, Braff DL, Mintz J. Neurocognitive deficits and functional outcome in schizophrenia: are we measuring the "right stuff"? Schizophr Bull. (2000) 26:119-36. doi: 10.1093/oxfordjournals.schbul.a033430

39. Green MF, Kern RS, Heaton RK. Longitudinal studies of cognition and functional outcome in schizophrenia: implications for MATRICS. Schizophr Res. (2004) 72:41-51. doi: 10.1016/j.schres.2004.09.009

40. Horan WP, Kern RS, Tripp C, Hellemann G, Wynn JK, Bell M, et al. Efficacy and specificity of Social Cognitive Skills Training for outpatients with psychotic disorders. J Psychiatr Res. (2011) 45:1113-22. doi: 10.1016/j.jpsychires.2011.01.015

41. Grande I, Berk M, Birmaher B, Vieta E. Bipolar disorder. Lancet (2016) 387:1561-72. doi: 10.1016/S0140-6736(15)00241-X

42. Solé B, Jiménez E, Torrent C, Reinares M, Bonnin CDM, Torres I, et al. Cognitive impairment in bipolar disorder: treatment and prevention strategies. Int J Neuropsychopharmacol. (2017) 20:670-80. doi: 10.1093/ijnp/pyx032

43. Carbon M, Correll CU. Thinking and acting beyond the positive: the role of the cognitive and negative symptoms in schizophrenia. CNS Spectr. (2014) 19(Suppl. 1):38-52, 53. doi:10.1017/S1092852914000601.

44. Bonnín CM, Yatham LN, Michalak EE, Martínez-Arán A, Dhanoa T, Torres I, et al. Psychometric properties of the well-being index (WHO-5) spanish version in a sample of euthymic patients with bipolar disorder. J Affect Disord. (2018) 228:153-9. doi: 10.1016/j.jad.2017. 12.006

45. Fett A-KJ, Viechtbauer W, Dominguez M-G, Penn DL, van Os J, Krabbendam L. The relationship between neurocognition and social cognition with functional outcomes in schizophrenia: a meta-analysis. Neurosci Biobehav Rev. (2011) 35:573-88. doi: 10.1016/j.neubiorev.2010.07.001

46. Green MF, Olivier B, Crawley JN, Penn DL, Silverstein S. Social cognition in schizophrenia: recommendations from the measurement and treatment research to improve cognition in schizophrenia new approaches conference. Schizophr Bull. (2005) 31:882-7. doi: 10.1093/schbul/sbi049

47. Salagre E, Solé B, Tomioka Y, Fernandes BS, Hidalgo-Mazzei D, Garriga $M$, et al. Treatment of neurocognitive symptoms in unipolar depression: a systematic review and future perspectives. J Affect Disord. (2017) 221:205-21. doi: 10.1016/j.jad.2017.06.034
48. Vieta E, Salagre E, Grande I, Carvalho AF, Fernandes BS, Berk M, et al. Early intervention in bipolar disorder. Am J Psychiatry (2018) 175:411-26. doi: 10.1176/appi.ajp.2017.17090972

49. Cella M, Reeder C, Wykes T. Group cognitive remediation for schizophrenia: exploring the role of therapist support and metacognition. Psychol Psychother Theor. (2016) 89:1-14. doi: 10.1111/papt.12062

50. Twamley EW, Jeste D V, Bellack AS. A review of cognitive training in schizophrenia. Schizophr Bull. (2003) 29:359-82. doi: 10.1093/oxfordjournals.schbul.a007011

51. Murru A, Pacchiarotti I, Nivoli AMA, Grande I, Colom F, Vieta E. What we know and what we don't know about the treatment of schizoaffective disorder. Eur Neuropsychopharmacol J Eur Coll Neuropsychopharmacol. (2011) 21:68090. doi: 10.1016/j.euroneuro.2011.03.001

52. Anaya C, Martinez Aran A, Ayuso-Mateos JL, Wykes T, Vieta E, Scott J. A systematic review of cognitive remediation for schizo-affective and affective disorders. J Affect Disord. (2012) 142:13-21. doi: 10.1016/j.jad.2012. 04.020

53. Moher D, Liberati A, Tetzlaff J, Altman DG. Preferred reporting items for systematic reviews and meta-analyses: the PRISMA statement. BMJ (2009) 339:b2535. doi: 10.1371/journal.pmed.1000097

54. Lahera G, Benito A, Montes JM, Fernández-Liria A, Olbert CM, Penn DL. Social cognition and interaction training (SCIT) for outpatients with bipolar disorder. J Affect Disord. (2013) 146:132-36. doi: 10.1016/j.jad.2012. 06.032

55. Lewandowski KE, Eack SM, Hogarty SS, Greenwald DP, Keshavan MS Is cognitive enhancement therapy equally effective for patients with schizophrenia and schizoaffective disorder? Schizophr Res. (2011) 125:291-4. doi: 10.1016/j.schres.2010.11.017

56. Scheu F, Aghotor J, Pfueller U, Moritz S, Bohn F, Weisbrod M, et al. Predictors of performance improvements within a cognitive remediation program for schizophrenia. Psychiatry Res. (2013) 209:375-80. doi: 10.1016/j.psychres.2013.04.015

57. Twamley EW, Burton CZ, Vella L. Compensatory cognitive training for psychosis: who benefits? who stays in treatment? Schizophr Bull. (2011) 37(Suppl. 2):S55-62. doi: 10.1093/schbul/sbr059

58. Higgins JPT, Altman DG, Gøtzsche PC, Jüni P, Moher D, Oxman AD, et al. The Cochrane Collaboration's tool for assessing risk of bias in randomised trials. BMJ (2011) 343:d5928. doi: 10.1136/bmj.d5928

59. Twamley EW, Vella L, Burton CZ, Heaton RK, Jeste DV. Compensatory cognitive training for psychosis. J Clin Psychiatry (2012) 73:1212-9. doi: 10.4088/JCP.12m07686

60. Bellucci DM, Glaberman K, Haslam N. Computer-assisted cognitive rehabilitation reduces negative symptoms in the severely mentally ill. Schizophr Res. (2003) 59:225-32. doi: 10.1016/S0920-9964(01) 00402-9

61. Grant N, Lawrence M, Preti A, Wykes T, Cella M. Social cognition interventions for people with schizophrenia: a systematic review focussing on methodological quality and intervention modality. Clin Psychol Rev. (2017) 56:55-64. doi: 10.1016/j.cpr.2017. 06.001

62. Eack SM, Greenwald DP, Hogarty SS, Cooley SJ, DiBarry AL, Montrose DM, et al. Cognitive enhancement therapy for earlycourse schizophrenia: effects of a two-year randomized controlled trial. Psychiatr Serv. (2009) 60:1468-76. doi: 10.1176/ps.2009.60. 11.1468

63. Wykes T, Huddy V, Cellard C, McGurk SR, Czobor P. A Metaanalysis of cognitive remediation for schizophrenia: methodology and effect sizes. Am J Psychiatry (2011) 168:472-85. doi: 10.1176/appi.ajp.2010. 10060855

64. Fiszdon JM, Cardenas AS, Bryson GJ, Bell MD. Predictors of remediation success on a trained memory task. J Nerv Ment Dis. (2005) 193:602-8. doi: 10.1097/01.nmd.0000177790.23311.ba

65. McGurk SR, Twamley EW, Sitzer DI, McHugo GJ, Mueser KT. A Meta-analysis of cognitive remediation in schizophrenia. Am J Psychiatry (2007) 164:1791-802. doi: 10.1176/appi.ajp.2007. 07060906 
66. Barlati S, Deste G, De Peri L, Ariu C, Vita A. Cognitive remediation in schizophrenia: current status and future perspectives. Schizophr Res Treat. (2013) 2013:156084. doi: 10.1155/2013/156084

67. Kurtz MM, Moberg PJ, Gur RC, Gur RE. Approaches to cognitive remediation of neuropsychological deficits in schizophrenia: a review and meta-analysis. Neuropsychol Rev. (2001) 11:197-210. doi: 10.1023/A:1012953 108158

68. Tomioka Y, Jiménez E, Salagre E, Arias B, Mitjans M, Ruiz V, et al. Association between genetic variation in the myo-inositol monophosphatase 2 (IMPA2) gene and age at onset of bipolar disorder. J Affect Disord. (2018) 232:229-36. doi: 10.1016/j.jad.2018. 02.002

69. Stern Y. Cognitive reserve in ageing and Alzheimer's disease. Lancet Neurol. (2012) 11:1006-12. doi: 10.1016/S1474-4422(12) 70191-6

70. Grande I, Sanchez-Moreno J, Sole B, Jimenez E, Torrent C, Bonnin CM, et al. High cognitive reserve in bipolar disorders as a moderator of neurocognitive impairment. J Affect Disord. (2017) 208:621-7. doi: 10.1016/j.jad.2016. 10.012

71. Anaya C, Torrent C, Caballero FF, Vieta E, Bonnin C del M, Ayuso-Mateos JL. Cognitive reserve in bipolar disorder: relation to cognition, psychosocial functioning and quality of life. Acta Psychiatr Scand. (2016) 133:386-98. doi: 10.1111 /acps. 12535

72. Amoretti S, Cabrera B, Torrent C, Mezquida G, Lobo A, González-Pinto A, et al. Cognitive reserve as an outcome predictor: first-episode affective versus non-affective psychosis. Acta Psychiatr Scand. (2018). doi: 10.1111/acps.12949. [Epub ahead of print].
Conflict of Interest Statement: IG has served as a consultant for Ferrer, advisor for Lundbeck, Otsuka and has been a speaker for Ferrer, Janssen and Lundbeck, Otsuka. EV has received grants and served as a consultant, advisor, or CME speaker for the following entities: AB-Biotics, Allergan, AstraZeneca, Bristol-Myers-Squibb, Ferrer, Forest Research Institute, Gedeon Richter, GlaxoSmith-Kline, Janssen, Lundbeck, Otsuka, Pfizer, Roche, Sanofi-Aventis, Servier, Shire, Sunovion, Takeda, Telefonica, the Brain and Behaviour Foundation, the Spanish Ministry of Science and Innovation (Centro de Investigación Biomédica en Red de Salud Mental), the Seventh European Framework Programme (European Network of Bipolar Research Expert Centres), and the Stanley Medical Research Institute.

The remaining authors declare that the research was conducted in the absence of any commercial or financial relationships that could be construed as a potential conflict of interest.

The reviewer RS and handling editor declared their shared affiliation at time of review.

Copyright (C) 2018 Lopez-Fernandez, Sole, Jimenez, Salagre, Gimenez, Murru, Bonnin, Amann, Grande, Vieta and Martínez-Aran. This is an open-access article distributed under the terms of the Creative Commons Attribution License (CC BY). The use, distribution or reproduction in other forums is permitted, provided the original author(s) and the copyright owner(s) are credited and that the original publication in this journal is cited, in accordance with accepted academic practice. No use, distribution or reproduction is permitted which does not comply with these terms. 